\title{
The cost and effect of expanding a Patient Tracer programme to identify and return patients loss to follow up at a large HIV Clinic in Trinidad
}

\section{R. Jeffrey Edwards ( $\sim$ jeffreye2000@gmail.com )}

University of the West Indies https://orcid.org/0000-0002-4392-8998

Nyla Lyons

Medical Research Foundation of Trinidad and Tobago

\section{Wendy Samaroo-Francis}

Medical Research Foundation of Trinidad and Tobago

Leon-Omari Lavia

Medical Research Foundation of Trinidad and Tobago

Isshad John

Medical Research Foundation of Trinidad and Tobago

\section{Selena Todd}

Medical Research Foundation of Trinidad and Tobago

Jonathan Edwards

Medical Research Foundation of Trinidad and Tobago

\section{Gregory Boyce}

Medical Research Foundation of Trinidad and Tobago

\section{Research}

Keywords: Patient tracing, HIV, sustainable, intervention

Posted Date: July 17th, 2020

DOI: https://doi.org/10.21203/rs.3.rs-41913/v1

License: (1) This work is licensed under a Creative Commons Attribution 4.0 International License.

Read Full License

Version of Record: A version of this preprint was published at AIDS Research and Therapy on April 23rd, 2021. See the published version at https://doi.org/10.1186/s12981-021-00341-3. 


\section{Abstract}

Background: Patients who default from HIV care are usually poorly adherent to antiretroviral treatment which results in suboptimal viral suppression. The study evaluated the effect and cost of expanding an intervention using two Patient Tracers to track and return to care patients lost to follow up at a large HIV Clinic in Trinidad.

Methods: Two Social Workers were trained as Patient Tracers and hired initially for 6 months (April September 2017), then extended to 15 months (April 2017 - June 2018) to call patients who were lost to follow up for 30 days or more during the period July 2016 - May 2018 at the HIV Clinic Medical Research Foundation of Trinidad and Tobago. Both the outcomes of the intervention, and costs were assessed over time.

Results: Over the 15 month period, of the of 2,473 patients who missed their scheduled visits for one month or more, 261 (10.6\%) patients were no longer in active care - 89 patients dead, 65 migrated, 55 hospitalized, 33 transferred to another treatment clinic and 19 incarcerated. Of the remaining 2,212 patients eligible for tracing, $1,794(81.1 \%)$ patients were returned to care at an average cost of $\$ 38.09$ USD per patient returned to care as compared to 589 of $866(68 \%)$ patients returned to care over the 6 month period $(p<0.001)$ at an estimated cost of $\$ 47.72$ USD per patient returned to care $(p<0.001)$. Of the 1,794 patients returned to care, 1,686 (94\%) were re-initiated/started on anti-retroviral therapy and $72.7 \%$ of these were virally suppressed (viral load $<1,000$ copies/ml) as of December 2018.

Conclusions: Patient Tracing is a feasible and effective intervention to identify and resolve the status of patients who are loss to follow up to bring these patients back into care with the aim of achieving viral suppression on antiretroviral therapy. Over time the effect of costs of patients returned to care demonstrated greater yields making patient tracing a sustainable intervention for programmes to identify and return patients to care.

\section{Background}

The use of anti-retroviral therapy (ART) which effectively suppresses the HIV viral load of patients results in reduced HIV transmission, reduced CD4 $+\mathrm{T}$ cell depletion and improved reconstitution of the immune system thereby transforming HIV into a chronic, manageable disease $(1,2,3,4)$. Thus lifelong management of patients with HIV infection requires long term retention on ART (5) which may prove quite challenging as the barriers to retention in HIV care should to be identified and addressed so that the individual and public health benefits of viral suppression can be achieved $(6,7,8,9)$. A systematic review of patient retention in antiretroviral programmes describing 39 cohorts of patients showed that $25 \%$ of patients were no longer on ART 24 months after initiation of treatment (10). Patients who are lost to follow up (LTFU) and non-adherent to ART are at increased risk for HIV transmission, HIV disease progression and subsequent mortality $(1,2,11,12)$, thus it is important to bring defaulters back into care $(13,14)$. The Medical Research Foundation of Trinidad and Tobago (MRFTT), the largest HIV clinic in 
Trinidad and Tobago and the Southern Caribbean, recently demonstrated that a patient tracing programme for HIV was practicable for re-engaging in care those patients who were LTFU (15). In this pilot programme, two social workers were trained as Patient Tracers and of 1058 patients who missed their scheduled visits for one month or more, 192 were no longer in active care (deceased, incarcerated, hospitalized, migrated or transferred to another clinic) and 866 were eligible for patient tracing (15). Of the 866 patients, 589 (68\%) were successfully contacted and returned to care (15).

Patient tracing programmes have been shown to be effective in determining the status of patients LTFU (14), however there have been mixed results in returning patients to care $(16,17,18)$. In a study by Tweya et al in Malawi, of 1158 patients LTFU and located by tracing, 74\% returned to care (16). Of patients LTFU, in Lusaka, Zambia, Krebs et al (17) successfully traced 430 (54\%) of 789 patients, however only one patient returned to care for every 18 home visits made (17) and in a community based antiretroviral therapy programme in Uganda, of 579 patients sampled for tracing, 61 (12.7\%) patients returned to care (18).

The purpose of the study was to evaluate the effect/outcome and costs of expanding an intervention using two Patient Tracers to track patients lost to follow up at the HIV Clinic, Medical Research Foundation of Trinidad and Tobago.

\section{Methods}

This was a retrospective study to track patients who missed their scheduled clinic visit for over one month and were deemed lost to follow up (LTFU) at the HIV Clinic, Medical Research Foundation of Trinidad and Tobago (MRFTT). As of June 30, 2018, a total of 6486 patients were reported to be enrolled active in care at the HIV Clinic. The patient tracing methods at the MRFTT are described elsewhere (15). The patient tracers (social workers) spent fifteen months (April 2017 -June 2018), five days per week, contacting patients via phone calls who missed their scheduled visits and did not return to the clinic for over 30 days during the period July 2016 - May 2018.

Inclusion criteria

Any patient attending the HIV clinic who missed their clinic visit for 30 days or more (lost to follow up) during the period July 2016 - May 2018.

Exclusion criteria

Any patient attending the HIV clinic who missed their clinic visit for less than 30 days (missed appointments) during the period July 2016 - May 2018.

Any patient attending the HIV clinic who did not miss clinic visits during the period July 2016 - May 2018. 
The source population was the patients attending the HIV Clinic, MRFTT during the period July 2016-May 2018. Generally, one patient tracer would follow up with one particular patient so that a relationship could be established and trust built up. "Treat all" started in September 2017 at the MRFTT and all patients who returned to care were offered or restarted on ART and followed up bi-weekly, then monthly, then three monthly and finally every six months once they were stable on ART and their HIV viral loads were suppressed.

All study protocols and procedures were reviewed and approved the University of the West Indies, Campus Research Ethics Committee, St. Augustine, Trinidad. De-identified patient data were extracted for analysis and the data were compiled to a flowchart to examine all the patients who returned to the clinic including those LTFU. The effects/outcomes and costs of expanding the patient tracing intervention were compared over two time periods. The pilot intervention was conducted over a six-month period April September 2017 where of 866 patients eligible for tracing, 589 (68\%) patients were successfully returned to care (15). The expanded programme was conducted over a fifteen-month period (April 2017 - June 2018). Both the start-up and implementation costs of the interventions were assessed. The data collected for the two time periods were collected, cleaned and organised into an excel spreadsheet database. This database was analysed using the Statistical Package for Social Sciences (SPSS version 21). The analysis consisted of a Pearson's chi-square test in order to determine if a statistically significant relationship existed between the different time periods and the number of patients returned to care as well as the cost of returning patients to care.

\section{Results}

Figure 1 shows the flow of patient outcomes through the study over the 15 month period, April 2017-June 2018 (extended programme). Of the sample of 2,473 patients who missed their scheduled visits for one month or more, it was determined that $261(10.6 \%)$ patients were no longer in active care. These included, 89 patients who were confirmed dead, 65 migrated, 55 hospitalized, 33 transferred to another treatment clinic and 19 incarcerated. Of the remaining 2,212 patients eligible for tracing, 302 (13.7\%) patients could not be reached up until the end of the study period and 1,910 (86.3\%) patients were contacted and rescheduled to return within the same week or their earliest availability. Of those who were reached, 116 did not show up for their rescheduled appointments, thus 1,794 (81.1\%) of 2,212 patients eligible for patient tracing were successfully returned to care (Fig. 1). Of these, 1,686 (94\%) were initiated/re-initiated on ART and $72.7 \%$ were virally suppressed (viral load $<1,000$ copies $/ \mathrm{ml}$ ) as of December 2018 .

The pilot phase of the programme took place over the 6 month period April-September 2017 and is published elsewhere (15). Of 1058 patients who missed their scheduled visits for one month or more, 866 were eligible for patient tracing and of these, $589(68 \%)$ were successfully contacted and returned to care (15) as compared to $1,794(81.1 \%)$ of 2,212 patients eligible for patient tracing who were successfully returned to care in the extended programme $(p<0.001)$. 
Both the start-up and implementation costs of the intervention were assessed (Table 1). The main cost of the intervention was the salary of the two Patient Tracers, who were employed in pilot phase of programme, initially for 6 months and then in extended programme for 15 months, and the costs of program management which included clerical support, office expenses, services and supplies and bus tickets, a small amount of petty cash (\$100USD/month), snack vouchers and high protein drinks which were given to patients in need (Table 1). The start-up costs i.e. the first month of intervention was $\$ 5,757$ USD per month. The total cost of the intervention in the pilot programme was $\$ 28,107.48$ USD and in the extended programme was $\$ 68,338.20$ USD. In pilot programme, 589 patients were returned to care at an estimated cost of $\$ 47.72$ USD per patient compared to 1,794 patients were returned to care in the extended programme (Table 2$)$ at an estimated to be $\$ 38.09$ USD per patient $(p<0.001)$.

Table 1

Estimated Costs of Returning Patients to Care at MRFTT April 2017 -June 2018

\begin{tabular}{|c|c|c|c|c|c|c|}
\hline \multirow{2}{*}{ Category } & \multirow[b]{2}{*}{ Item } & \multicolumn{2}{|c|}{ Startup costs } & \multicolumn{3}{|c|}{ Implementation costs } \\
\hline & & $\begin{array}{l}\# \\
\text { units }\end{array}$ & $\begin{array}{l}\text { Initial costs/ } \\
\text { month one }\end{array}$ & $\begin{array}{l}\text { Recurring } \\
\text { Costs/over } \\
\text { months }\end{array}$ & 5 & $\begin{array}{l}\text { Recurring } \\
\text { Costs/over } \\
\mathbf{1 4} \text { months }\end{array}$ \\
\hline \multirow{2}{*}{$\begin{array}{l}\text { Personnel } \\
\text { salaries }\end{array}$} & Patient Tracers & 2 & $\$ 3,582.08$ & $\$ 17,910.40$ & & $\$ 50,149.12$ \\
\hline & $\begin{array}{l}\text { Program } \\
\text { Management }\end{array}$ & 1 & $\$ 700$ & $\$ 3,500$ & & $\$ 9,800$ \\
\hline \multirow[t]{3}{*}{ Equipment } & Laptop & 2 & $\$ 491$ & $\$ 0.00$ & & $\$ .00$ \\
\hline & Cell Phones & 2 & $\$ 188$ & $\$ 940$ & & $\$ 2,632$ \\
\hline & Workstations & 2 & $\$ 296$ & $\$ 0.00$ & & $\$ 0.00$ \\
\hline Contractual & Training & 1 & $\$ 500$ & $\$ 0.00$ & & $\$ 0.00$ \\
\hline \multicolumn{3}{|l|}{ Subtotal } & $\$ 5,757.08$ & $\$ 22,350.40$ & & $\$ 62,581.12$ \\
\hline \multirow{2}{*}{\multicolumn{4}{|c|}{$\begin{array}{l}\text { Total Programme Costs (Startup costs + } \\
\text { Implementation costs) }\end{array}$}} & \multicolumn{2}{|l|}{$\$ 28,107.48$} & $\$ 68,338.20$ \\
\hline & & & & \multicolumn{2}{|c|}{ Over 6 Months } & $\begin{array}{l}\text { Over } 15 \\
\text { Months }\end{array}$ \\
\hline
\end{tabular}

Table 2

Comparison the number of patients returned to care and the costs over two time periods 


\begin{tabular}{|c|c|c|c|}
\hline & \multirow{2}{*}{$\begin{array}{l}\text { Pilot Programme } \\
\text { April } 2017 \text { - September } \\
2017\end{array}$} & \multirow{2}{*}{$\begin{array}{l}\text { Expanded } \\
\text { Programme } \\
\text { April 2017- June } \\
2018\end{array}$} & \multirow[t]{2}{*}{$\begin{array}{l}\mathrm{p} \\
\text { value }\end{array}$} \\
\hline & & & \\
\hline $\begin{array}{l}\text { Number of patients eligible for } \\
\text { tracing }\end{array}$ & 866 & 2212 & \\
\hline Number of patients returned to care & $589(68 \%)$ & $1794(81.1 \%)$ & $<0.001$ \\
\hline $\begin{array}{l}\text { Average cost per patient returned to } \\
\text { care }\end{array}$ & US\$47.72 & US\$38.09 & $<0.001$ \\
\hline
\end{tabular}

Of the 1,794 patients returned to care, 1,686 (94\%) were re-initiated/started on ART and $72.7 \%$ of these were virally suppressed (viral load $<1,000$ copies/ml) as of December 2018. This intervention was successful in resolving status of patients who were LTFU and was effective as there was a very good yield of patients (81.1\%) returned to care. The average cost of resolving the status of all the patients LTFU, including those who could not be found through tracing (2,473 patients) is estimated to be $\$ 27.63$ USD per patient over the period.

\section{Discussion}

During the 15 month extended programme, two patient tracers working 5 days per week were able to determine the status of 1910 (86.3\%) of 2,212 patients who were identified as LTFU and eligible for patient tracing. The intervention resulted in returning $1,794(81.1 \%)$ of 2,212 patients to care as compared to 589 of 866 (68\%) patients successfully contacted and returned to care in the 6 month pilot programme $(p<0.001)$. Thus the effect of the intervention improved over time as more patients were successfully returned to care which may be attributed to the enhanced efficiency of the patient tracing programme as the patient tracers became more proficient at calling patients LTFU and getting them back into care; due to cultivated relationships between the patient tracers and staff from other treatment sites so that patient transfers among sites were more readily ascertained and the MRFTT started a prison programme in January 2018 so that incarcerated patients could be readily identified. In addition, "treat all' was introduced in September 2017, before this ART was indicated for patients at MRF whose CD4 counts fell below 350 cells $/ \mathrm{mm}^{3}$, so some patients defaulted from clinic as they claimed no treatment was offered to them as their CD4 cell count was "stable". During the phone calls, the patient tracers explained to the patients the benefits of ART and assured them that once they returned to clinic, ART would be initiated/reinitiated.

The total cost of the intervention in the pilot programme was $\$ 28,107.48$ USD and in the extended programme was $\$ 68,338.20$ USD. During the pilot phase, a total of 589 patients were returned to care at an estimated cost of $\$ 47.72$ USD per patient returned compared to 1,794 patients were returned to care in the extended programme at an estimated to be $\$ 38.09$ USD per patient returned $(p<0.001)$. In the study by Rosen and Ketlhapile in South Africa, 20 of 97 patients (21\%) LTFU were returned to care by patient 
tracing at a cost of $\$ 432$ USD per patient, which was quite expensive and unsustainable (19). In our study, the start-up costs of the intervention was $\$ 5,757$ USD for the first month and then $\$ 4,407.08$ USD per month thereafter but the high yield of patients returned to care $(81.1 \%)$ demonstrated its feasibility and effectiveness.

To improve the efficiency of the patient tracing intervention, it is recommended that Trinidad and Tobago (with a population of approximately 1.37 million inhabitants) invest in a National Health Management Information System (HMIS) to link and track HIV cases/patients who transfer to other treatment facilities/clinics which would result in enhanced tracking and monitoring of patients across sites. Improved reporting of deaths and linking the national death registry to a HIV case surveillance HMIS can also be effective in validating the status of patients not active in care and LTFU (19) as well as strengthening active HIV case surveillance in hospitals and in the prisons to assist in identifying patients who are hospitalized and incarcerated.

The data and outcomes of this study assisted in allocation of programme resources for targeted interventions to reduce LTFU and increase patient retention in HIV care through a tailored package of HIV services to better serve the needs patients enrolled in HIV care (20) to include, defaulters, youth, nonvirally suppressed patients and the prison population. The MRFTT clinic implemented models of Differentiated Service Delivery (DSD) (21) using a client driven approach to increase patient retention in HIV care, ART adherence and viral suppression. For example, the clinic operating hours were extended during the weekdays (15) and Saturday morning sessions were launched targeting patient defaulters and those newly initiated on ART. Patient/Peer Advocates (15) were trained to mentor and assist patients to overcome the barriers to ART adherence and retention during dedicated clinic visits (15). A once -per month prison outreach program was implemented to improve ART retention among prisoners living with HIV who were incarcerated. The MRFTT also implemented a monthly youth focused clinic targeting young persons living with HIV aged 18-25 years with a package of services to include text message reminders and enhanced psychosocial care to retain youth PLHIV on ART.

As in the pilot programme, the three most common barriers to engagement in care included not remembering their appointments, difficulty getting time off from work and fear of being seen attending the HIV clinic (15). Within two days of missing their clinic visits (missed appointments), the clinic nurses would call these patients to reschedule their appointments and the MRFTT introduced a text messaging pilot programme for patients attending the Youth Clinic (reminding patients about their upcoming appointments) which is due to be extended to the entire clinic population by August 2020. Patients also reported not keeping their clinic appointment due to long waiting times at the clinic, and feelings of shame and stigmatization attending the clinic. To address these barriers, the clinic implemented differentiated services via an evening/after work clinic offering a client friendly environment (15), referrals to peer/patient advocates to address stigma and the importance of retention in care and viral suppression (15) and expedited care for patient defaulters. 
One of the major challenges encountered by the patient tracers was patients who were unable to attend clinic due to financial issues. In this instance, the patient tracers would call and inform the patient of the availability of bus tickets, meal vouchers and high protein drinks once they visit clinic. In a few instances, the patients indicated that they had no funds to travel to the clinic, the patient tracers would ask the patient if they can borrow transport money from a relative or friend and assured them that this would be returned to them from petty cash once they attended clinic and that they would be referred to the social worker who would assist with financial and support services. Another challenge is that defaulters often change their phone numbers and often do not inform the clinic of these changes. The patient tracers would search the electronic patient records (EPR) to determine if a next of kin (NOK) and their contact numbers was listed in the patient's records and if the patient disclosed their HIV status to the next of kin (which is recorded in the EPR). In this case, the NOK was then contacted as conduit to assist in reaching the patient.

If patients are not ready to return to care, they tend to be very uncooperative and would sometimes 'block' their phone number to avoid contact. In cases like this, the primary patient tracer would use a different phone number to call or ask the second tracer to establish contact. It is noteworthy, that after several months of unsuccessful attempts, some clients may eventually "unblock" the patient tracer's phone number especially if they are feeling unwell or if they are desirous of returning to clinic.

Some patients reported that they defaulted from HIV care because they felt pressured by clinic staff to initiate ART when they were not ready to start. If patients were not ready to initiate medication, the patient tracers would try to help patients identify the barriers to ART initiation and assist patients though counseling to overcome these barriers. For patients who have not disclosed their HIV status to their partners for fear of intimate partner violence or that the partner may leave the relationship or having to answer awkward questions if they are seen taking medication, the patient tracers screened the patients and referred them to come in to clinic and seek assistance from a counsellor.

The ability of the patient tracers to identify and resolve the patient challenges and successfully reintegrate them into HIV care further highlights the effectiveness of this intervention. The intervention was critical in reinitiating patients on ART or initiating ART in patients who defaulted clinic and were ART naïve with the aim of achieving HIV viral suppression and reduced HIV transmission. Of the 1,794 patients returned to care, $1,686(94 \%)$ were re-initiated/started on ART and $72.7 \%$ of these were virally suppressed (viral load $<1,000$ copies $/ \mathrm{ml}$ ) as of December 2018. Given these outcomes, the Patient Tracing Programme was critical in reducing treatment interruptions which if left unattended may lead to high levels of viremia with attendant risks of increasing HIV transmission, the potential for drug resistance, the development of opportunistic infections (22), subsequent hospitalization and high costs to the health care system (23).

There were some limitations to the study as the estimate of the costs does not take into consideration other outcomes of the patient tracing programme. For example, resolving the status of patients deemed LTFU improved the accuracy of the data in the EPR (19); by ascertaining the common barriers to retention 
in care, the MRFTT was able to put in place a DSD model of care targeting defaulters with an enhanced package of services as a result of the intervention; some patients may have returned to care after the study concluded or some patients may have transferred to other clinics closer to their homes (thereby reducing transportation costs) on the advice of the patient tracers (19).

\section{Conclusions}

Patient Tracing is a feasible and effective intervention to identify and resolve the status of patients who are loss to follow up and to bring these patients back into care so that ART can be started/reinitiated with the aim of achieving viral suppression. Over time the effect of costs of patients returned to care demonstrated greater yields making patient tracing a sustainable intervention for programmes to identify and return patients to care.

\section{Abbreviations}

ART

antiretroviral therapy

DSD

Differentiated service delivery

EPR

Electronic patient records

HMIS

Health management information system

LTFU

Lost to follow up

MRFTT

Medical Research Foundation of Trinidad and Tobago

\section{Declarations}

\section{Ethics declaration}

The study protocol was reviewed and approved by the institutional review board of the University of the West Indies, St. Augustine Trinidad.

\section{Consent for publication}

Not applicable - The manuscript does not contain data from any individual person

\section{Availability of data and materials}


The datasets used and/or analyzed during the study are available from the corresponding author (RJE) on reasonable request.

\section{Competing interests}

The authors declare they have no competing interests.

\section{Funding}

The study received financial support from the President's Emergency Fund for AIDS Relief (PEPFAR) through a grant to the Trinidad Tobago Ministry of Health, Program Number CDC-RFA-GH16-1608. The funder had no role in the study design, data collection, data analysis or writing of the report.

\section{Authors' contributions}

Study design and operation: RJE, NL, WSF. Follow up and assessments: RJE, IJ, ST, GB. Statistical analysis: LOL, NL. Manuscript preparation: RJE, NL, WSF, IJ, ST, JE, GB. We affirm that all authors contributed to the manuscript. All authors read and approved the final manuscript.

\section{Acknowledgement}

The investigators thank the staff of the Medical Research Foundation of Trinidad and Tobago for their support during the study.

\section{References}

1. Quinn TC. HIV epidemiology and the effects of antiviral therapy on long-term consequences. AIDS. 2008 Sep;22(Suppl 3):7-12. doi:10.1097/01.aids.0000327510.68503.e8. Suppl 3 ) .

2. Cohen MS, Chen YQ, McCauley M, Gamble T, Hosseinipour MC, Nagalingeswaran K, Fleming TR, et al. Prevention of HIV-1 Infection with Early Antiretroviral Therapy. N Engl J Med. 2011 Aug;11(6):493-505. doi:10.1056/NEJMoa1105243. Epub 2011 Jul 18. 365 ) .

3. 10.1016/S0140-6736(13)61809-7

Deeks SG, Lewin SR, Havlir DV. The End of AIDS: HIV Infection as a Chronic Disease. Lancet. 2013 Nov 2;382(9903):1525-33. doi: 10.1016/S0140-6736(13)61809-7.

4. Autran B, Carcelaint G, Li TS, Gorochov G, Blanc C, Renaud M, Durali M, Mathez D, Calvez V, Leibowitch J, Katlama C, Debré P. Restoration of the Immune System With Anti-Retroviral Therapy Immunol Lett. 1999 Mar;66(1-3):207-11. doi: 10.1016/s0165-2478(98)00159-x. 
5. Bisson GP, Stringer JS. 'Lost but not forgotten-the economics of improving patient retention in AIDS treatment programs' PLoS One. 2009;6(10) doi:10.1371/journal.pmed.1000174.

6. Holtzman CW, Brady KA, Yehia BR. Retention in Care and Medication Adherence: Current Challenges to Antiretroviral Therapy Success Drugs. 2015 Apr;75(5):445-54. doi: 10.1007/s40265-015-0373-2.

7. Giordano TP, Gifford AL, White AC, et al. Retention in care: a challenge to survival with HIV infection. Clin Infect Dis. 2007;44(11):1493-9.

8. Garcia de Olalla P, Knobel H, Carmona A, Guelar A, Löpez-Colomes JL, Caylä JA. Impact of adherence and highly active antiretroviral therapy on survival in HIV-infected patients. J Acquir Immune Defic Syndr. 2002;30(1):105-10.

9. Edwards RJ, Cyrus E, Bhatt C, Lyons N, Lavia LO, Boyce G. Viral suppression among persons living with HIV in Trinidad \& Tobago: Implications for targeted prevention programmes. Glob Public Health. 2019 Nov;14(11):1569-1577. doi: 10.1080/17441692.2019.1633379.

10. Fox MP, Rosen S. Patient retention in antiretroviral therapy programs up to three years on treatment in sub-Saharan Africa, 2007-2009: systematic review. Trop Med Int Health. 2010;15(s1):1-15. doi:10.1111/j.1365-3156.2010.02508.x.

11. Bangsberg DR, Perry $S$, Charlebois ED, et al. Non-adherence to highly active antiretroviral therapy predicts progression to AIDS. AIDS. 2001;15(9):1181-3.

12. Hogg RS, Heath $\mathrm{K}$, Bangsberg $\mathrm{D}$, et al. Intermittent use of triple-combination therapy is predictive of mortality at baseline and after 1 year of follow-up. AIDS. 2002;16(7):1051-8.

13. Thomson KA, Cheti EO, Reid T. Implementation and Outcomes of an Active Defaulter Tracing System for HIV, Prevention of Mother to Child Transmission of HIV (PMTCT), and TB Patients in Kibera, Nairobi, Kenya Trans R Soc Trop Med Hyg. 2011 Jun;105(6):320-6. doi:

10.1016/j.trstmh.2011.02.011.

14. 10.1111/j.1365-3156.2010.02507.x

Geng EH, Gliddin DV, Emenyonu N, Musinguzi N, Bwana MB, Neilands TB, Martin JN. (2010). Tracking a sample of patients lost to follow-up has a major impact on understanding determinants of survival in HIV-infected patients on antiretroviral therapy in Africa. Tropical Medicine \& International Health 2010;15(Supplement 1):63-69. doi:https://doi.org/10.1111/j.13653156.2010.02507.x.

15. Jeffrey Edwards R, Lyons N, Bhatt C, Samaroo-Francis W, Hinds A, Cyrus E. Implementation and outcomes of a patient tracing programme for HIV in Trinidad and Tobago Glob Public Health. 2019 Nov;14(11):1589-1597. doi: 10.1080/17441692.2019.1622759.

16. Tweya H, Gareta D, Chagwera F, Ben-Smith A, Mwenyemasi J, Chiputula F, Boxshall M, Weigel R, Jahn A, Hosseinipour M, Phiri S. Early Active Follow-Up of Patients on Antiretroviral Therapy (ART) Who Are Lost to Follow-Up: The 'Back-to-Care' Project in Lilongwe. Malawi Trop Med Int Health. 2010 Jun;15(Suppl 1):82-9. doi:10.1111/j.1365-3156.2010.02509.x.

17. Krebs DW, Chi BH, Mulenga Y, Morris M, Cantrell RA, Mulenga $L$, et al. Community-based follow-up for late patients enrolled in a district-wide programme for antiretroviral therapy in Lusaka, Zambia. AIDS 
Care. 2008;20:311-7. doi:10.1080/09540120701594776.

18. 10.1097/FTD.0b013e3182526e6a

Alamo ST, Colebunders R, Ouma J, Sunday P, Wagner G, Wabwire-Mangen F, Laga M. Return to Normal Life After AIDS as a Reason for Lost to Follow-Up in a Community-Based Antiretroviral Treatment Program. J Acquir Immune Defic Syndr. 2012 Jun 1;60(2):e36-45. doi:

10.1097/FTD.0b013e3182526e6a.

19. Rosen S, Ketlhapile M. Cost of using a patient tracer to reduce loss to follow-up and ascertain patient status in a large antiretroviral therapy program in Johannesburg, South Africa. Tropical Med Int Health. 2010;15(s1):98-104.

20. Okeke NL, Ostermann J, Thielman NL. Enhancing Linkage and Retention in HIV Care: a Review of Interventions for Highly Resourced and Resource-Poor Settings. Curr HIV/AIDS Rep. 2014 Dec;11(4):376-92. doi:10.1007/s11904-014-0233-9.

21. The International AIDS Society Differentiated care for HIV: A decision framework for Antiretroviral Therapy Delivery

The International AIDS Society Differentiated care for HIV: A decision framework for Antiretroviral Therapy Delivery. Geneva S. 2016. Available from:

http://www.differentiatedcare.org/Portals/0/adam/Content/yS6M-

GKB5EWs_uTBHk1C1Q/File/Decision\%20Framework.pdf.

22. Fonsah JY, Njamnshi AK, Kouanfack C, Qiu F, Njamnshi DM, Tagny CT, Nchindap E, Kenmogne L, Mbanya D, Heaton R, Kanmogne GD. Adherence to Antiretroviral Therapy (ART) in YaoundéCameroon: Association With Opportunistic Infections, Depression, ART Regimen and Side Effects. PLoS One. 2017 Jan 31;12(1):e0170893. doi: 10.1371/journal.pone.0170893.

23. Fielden SJ, Rusch ML, Yip B, Wood E, Shannon K, Levy AR, Montaner JS, Hogg RS. Nonadherence Increases the Risk of Hospitalization Among HIV-infected Antiretroviral Naive Patients Started on HAART. J Int Assoc Physicians AIDS Care (Chic). 2008 Sep-Oct;7(5):238-44.

doi:10.1177/1545109708323132.

\section{Figures}




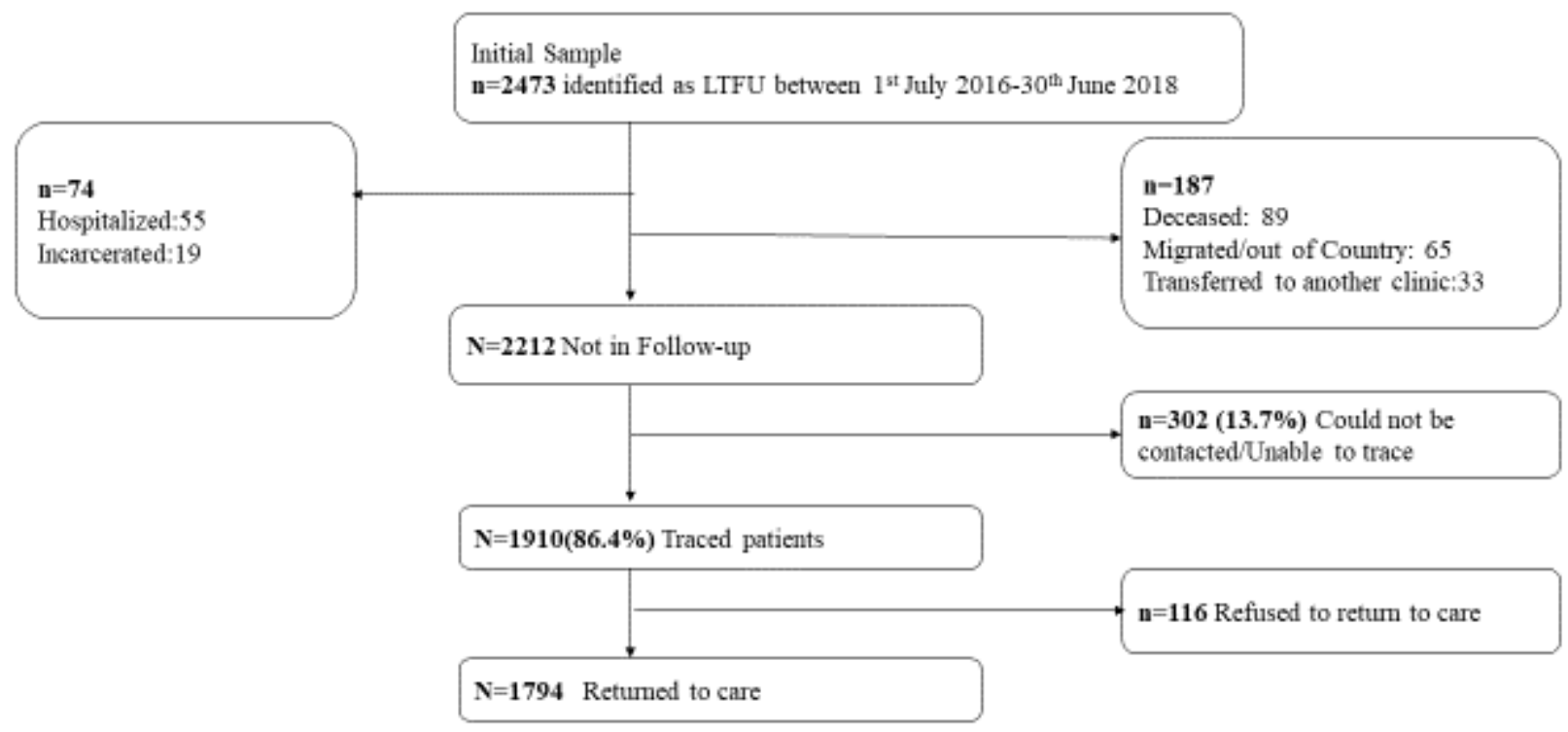

\section{Figure 1}

Flow of patient outcomes through the study 